\title{
Malignant germ cell tumours in the elderly: a histopathological review of 50 cases in men aged 60 years or over
}

\author{
Daniel M Berney ${ }^{1}$, Anne Y Warren ${ }^{2}$, Monika Verma ${ }^{1}$, Sak Kudahetti ${ }^{1}$, Jane M Robson ${ }^{3}$, \\ Michael W Williams ${ }^{3}$, David E Neal ${ }^{4}$, Thomas Powles ${ }^{5}$, J Shamash ${ }^{5}$ and \\ R Timothy D Oliver ${ }^{5}$
}

\begin{abstract}
${ }^{1}$ Department of Histopathology, Barts and The London School of Medicine and Dentistry, St Bartholomew's Hospital, West Smithfield, London, UK; ${ }^{2}$ Department of Histopathology, Addenbrooke's Hospital, Cambridge, UK; ${ }^{3}$ Department of Medical Oncology, Addenbrooke's Hospital, Cambridge, UK; ${ }^{4}$ Department of Urology, Addenbrooke's Hospital, Cambridge, UK and ${ }^{5}$ Department of Medical Oncology, Barts and The London School of Medicine and Dentistry, St Bartholomew's Hospital, West Smithfield, London, UK
\end{abstract}

\begin{abstract}
Malignant testicular germ cell tumours in the elderly are extremely rare with anecdotal accounts of their aggressive behaviour. Fifty cases of germ cell tumour, diagnosed at the age of 60 years or above, were pathologically reviewed. The oldest patient was 86 years of age, with $78 \%$ of cases presenting in men in their 60 s. Forty-one $(82 \%)$ of the tumours were seminomas with only nine cases $(18 \%)$ of mixed or nonseminomatous germ cell tumour. However, all non-seminomatous types of tumour were represented in the series. The macroscopic tumour size was significantly larger (median $=6 \mathrm{~cm}$, range $=2-11 \mathrm{~cm}$ ) than comparable series in younger men. They were also of higher stage with more frequent vascular invasion and rete testis invasion than is typically seen in a younger population. The tumours were less associated with intratubular germ cell neoplasia than in younger men as it was present in only $47 \%$ of assessable cases. We conclude that germ cell tumours, in man aged 60 years or above, present at a later stage than in younger men, and although most are seminomas, non-seminomatous tumours may occur with a wide spectrum of morphology. Modern Pathology (2008) 21, 54-59; doi:10.1038/modpathol.3800978; published online 2 November 2007
\end{abstract}

Keywords: seminoma; germ cell tumour; elderly

Germ cell tumours are the commonest malignancy in young males. Their incidence over the past 30 years, particularly in Europe and the USA, has increased. ${ }^{1,2}$ The vast majority of tumours are diagnosed in the third and fourth decade of life. Rare prepubescent malignant germ cell tumours are also recorded ${ }^{3}$ but they are usually very different in their histopathological profile and behaviour, being unassociated with intratubular germ cell neoplasia, unclassified (IGCNU) and are usually pure teratomas or yolk sac tumours.

The incidence of malignant germ cell tumours declines markedly towards the age of 50 , and tumours in patients above the age of 60 are extremely rare. A slight peak in testicular tumours

Correspondence: Dr DM Berney, FRCPath, Department of Histopathology, The Royal London Hospital, 80 Newark Street, London E1 2ES, UK.

E-mail: danberney@hotmail.com

Received 12 June 2007; revised 22 August 2007; accepted 05 September 2007; published online 2 November 2007 seen in the elderly is thought to be due to secondary neoplasms involving the testis. Spermatocytic seminomas are an entirely separate lesion from the remainder of the germ cell tumours. ${ }^{4}$ They are well reported in the elderly and have a distinct morphology and immunophenotype. IGCNU is never present. There are virtually no established cases of metastatic pure spermatocytic seminomas, which therefore almost always has a benign outcome. Incredibly rare exceptions include those cases of spermatocytic seminomas that develop sarcomatous change within them. Recent evidence suggests that they are derived from primary spermatocytes whereas the remainder of the germ cell tumours are derived from more primitive germ cells. ${ }^{5}$ The vast majority of men presenting with a testicular lump in the 60 and above age group have a spermatocytic seminomas or a primary lymphoma, or a stromal tumour, usually of Leydig cell type. Rarely metastases can also be seen.

This review was initiated 4 years ago due to the authors' clinical and pathological experience, 
gained in phase 2 trials of novel treatments for relapsed germ cell tumours, ${ }^{6}$ that elderly men with germ cell tumours tended to present late, and responded more poorly to chemotherapy when compared with younger men. Due to their rarity, even in referral practice, a retrospective cohort has been collected from a number of sources.

We here report a unique series of 50 malignant germ cell tumours, diagnosed at the age of 60 years or over, which specifically excluded spermatocytic seminomas. The purpose of this was to give an insight into the differences in presentation, macroscopic appearances, spectrum of diagnoses and other histopathological parameters when compared with malignant germ cell tumours diagnosed in a younger population.

\section{Materials and methods}

Cases for review were collected from a number of sources. The British Testicular Tumour Panel was a group of genito-urinary pathologists led by R Pugh, who examined referral cases from around the United Kingdom between 1950 and 1980. Slides or blocks from 28 cases were available for review, as well as the panel's histopathological reports.

Other cases were collected from the archives of Barts and The London NHS Trust (12 cases) and Addenbrooke's Hospital (10 cases) and included referral cases.

The cases were reviewed by an expert genitourinary pathologist (DB and AW), and if necessary, immunochemistry was performed to confirm the diagnosis. The cases in the British Testicular Tumour Panel, where blocks were available, had been tissue micro-arrayed onto seven blocks. Immunohistochemistry for placental alkaline phosphatase had been performed previously on these arrays and positivity was confirmed in all the submitted cases of seminoma.

Data recorded included patient age, side of tumour, macroscopic size of tumour, histopathological diagnosis, presence of vascular invasion, rete testis invasion, tunica vaginalis invasion, cord invasion and the presence of IGCNU.

\section{Results}

The cases are displayed in Table 1. The age profile is displayed in Figure 1. The average age was 67 years with the oldest person diagnosed being 86. There was a sharp decline in cases over the age of 70 , although interestingly cases appeared stable in frequency between 60 and 70 .

Forty-one of the tumours were seminomas (82\%). Three of these had significant numbers of syncytiotrophoblastic cells (7\%). The only other pure tumour type seen were two embryonal carcinomas, there being no pure yolk sac tumours, teratomas or pure choriocarcinomas. Mixed tumours included six non-seminomas $(12 \%)$ and three mixed seminomas/non-seminomas $(6 \%)$. Yolk sac was seen in four of these tumours (8\%), teratoma in six (12\%), embryonal carcinoma in six (12\%) and choriocarcinoma in one $(2 \%)$.

Vascular invasion was seen in 18 cases (36\%). Rete testis invasion was seen in 26 out of 37 cases $(70 \%)$. We attempted to elucidate the stage, although this was not possible in many cases due to limited blocks and slides being available. In total there were eleven T1, three T2, eight T3 and two T4 cases.

The side of the tumour was reported in 39 cases, $24(61 \%)$ were right sided and 15 (39\%) left sided. Tumour size was available on 26 cases where the macroscopic size had been recorded clinically or pathologically. The size of tumour ranged from 2 to $11 \mathrm{~cm}$ with a median of $6 \mathrm{~cm}$, mean of $6.0 \mathrm{~cm}$ and a s.d. of $2.7 \mathrm{~cm}$. The mean diameter of the 13 tumours that were diagnosed within the past 10 years show a mean diameter of $5.6 \mathrm{~cm}$.

As review material was sometimes limited, with only one block available (especially on the British Testicular Tumour Panel series where there was almost never any seminiferous tubules to assess) only 19 of the tumours had sufficient adjacent seminiferous tubules to assess the presence of IGCNU. At least 50 tubules had to be present to justify inclusion. Out of which 8/17 (47\%) showed IGCNU, with atrophic features present in 11/17 $(65 \%)$.

\section{Discussion}

Germ cell tumours are a success story for modern chemotherapy and radiotherapy, with a high cure rate. ${ }^{7}$ Often, if first-line therapy fails, then secondor even third-line regimens are available at specialist centres. Therefore, any group of these patients where the cure rate falls significantly below the average is a cause for further investigation. Malignant germ cell tumours in the elderly are therefore a cause for concern.

The study of 729 seminomas in the series of the British Testicular Tumour Panel, some of which has been included in the current series, revealed 7 seminomas in men above the age of $70 .{ }^{8}$ However, not all of these cases have been included, as not all slides for review were present in the pathological files. Germ cell tumours in the elderly have been reported sporadically in the past. One report of seminoma dates back 50 years. ${ }^{9}$ One previous series deals specifically with testicular tumours in men 60 or over. ${ }^{10}$ They are also mentioned en passant as part of larger series. ${ }^{8,11-14}$ The incidence of malignant germ cell tumours compared to other testicular neoplasms in the elderly is difficult to determine due to differences in classification. Fortunately, most authors have used the age of 60 as a cutoff. Abell and Holtz ${ }^{10}$ reported 12 malignant germ cell tumours out of a total of $50(24 \%)$ diagnosed at age 
Table 1 List of germ cell tumours diagnosed at age 60 or over with pathological data

\begin{tabular}{|c|c|c|c|c|c|c|c|}
\hline $\begin{array}{l}\text { Patient } \\
\text { no. }\end{array}$ & Age & Diagnosis & $\begin{array}{l}\text { Side of } \\
\text { tumour }\end{array}$ & $\begin{array}{l}\text { Tumour } \\
\text { diameter }\end{array}$ & $\begin{array}{l}\text { Vascular } \\
\text { invasion }\end{array}$ & $\begin{array}{l}\text { Rete testis } \\
\text { invasion }\end{array}$ & $\begin{array}{l}\text { Seminiferous } \\
\text { tubules }\end{array}$ \\
\hline $1^{\mathrm{a}}$ & 60 & Seminoma & Right & NA & Yes & Yes & NS \\
\hline $2^{\mathrm{a}}$ & 69 & Seminoma & Right & 7.6 & No & NA & NS \\
\hline $3^{\mathrm{a}}$ & 60 & Seminoma & Right & 4.0 & No & Yes & NS \\
\hline $4^{a}$ & 61 & Seminoma & Right & 5.0 & No & Yes & NS \\
\hline $5^{\mathrm{a}}$ & 61 & Seminoma & Left & 4.0 & No & No & NS \\
\hline $6^{\mathrm{a}}$ & 68 & Seminoma & Left & NA & Yes & Yes & NS \\
\hline $7^{\mathrm{a}}$ & 69 & Seminoma & NA & NA & No & NA & NS \\
\hline $8^{\mathrm{a}}$ & 69 & Seminoma & NA & 5.0 & Yes & Yes & NS \\
\hline $9^{\mathrm{a}}$ & 67 & Seminoma & NA & NA & No & Yes & NS \\
\hline $10^{\mathrm{a}}$ & 67 & Seminoma & Left & NA & No & NA & NS \\
\hline $11^{\mathrm{a}}$ & 66 & Seminoma & Right & 8.0 & Yes & Yes & NS \\
\hline $12^{\mathrm{a}}$ & 70 & Seminoma & Left & NA & No & NA & IGCNU, atrophy \\
\hline $13^{\mathrm{a}}$ & 60 & Seminoma & Right & NA & No & Yes & NS \\
\hline $14^{\mathrm{a}}$ & 68 & $\mathrm{~S}$ with TGC & NA & NA & No & NA & NS \\
\hline $15^{\mathrm{a}}$ & 73 & S/NSGCT:EC,T & Right & 11.0 & No & NA & NS \\
\hline $16^{\mathrm{a}}$ & 62 & $\mathrm{~S}$ with TGC & Left & 10.0 & Yes & NA & NS \\
\hline $17^{\mathrm{a}}$ & 67 & Seminoma & Right & 8.0 & Yes & Yes & IGCNU \\
\hline $18^{\mathrm{a}}$ & 62 & Seminoma & Left & NA & No & No & NS \\
\hline $19^{\mathrm{a}}$ & 60 & Seminoma & Right & NA & No & Yes & NS \\
\hline $20^{\mathrm{a}}$ & 63 & NSGCT:T,YST & Left & NA & No & NA & NS \\
\hline $21^{\mathrm{a}}$ & 69 & S with TGC & Right & NA & No & No & IGCNU, atrophy \\
\hline $22^{\mathrm{a}}$ & 79 & Seminoma & Left & NA & No & NA & NS \\
\hline $23^{\mathrm{a}}$ & 79 & Seminoma & Right & 3 & Yes & Yes & NS \\
\hline $24^{\mathrm{a}}$ & 63 & Seminoma & Right & NA & No & NA & NS \\
\hline $25^{\mathrm{a}}$ & 68 & Seminoma & Right & NA & Yes & Yes & NS \\
\hline $26^{\mathrm{a}}$ & 63 & Seminoma & Right & 7.0 & Yes & Yes & NS \\
\hline $27^{\mathrm{a}}$ & 68 & Seminoma & Right & 2.0 & Yes & Yes & NS \\
\hline $28^{\mathrm{a}}$ & 67 & Seminoma & NA & 10.0 & No & Yes & NS \\
\hline $29^{\mathrm{b}}$ & 64 & S/NSGCT:T,EC & NA & 6.0 & No & Yes & NS \\
\hline $30^{\mathrm{b}}$ & 64 & $\begin{array}{l}\text { S/NSGCT:T+adenocarcinoma } \\
\text { somatic transformation }\end{array}$ & Left & NA & No & No & Normal \\
\hline $31^{\mathrm{b}}$ & 60 & Seminoma & NA & NA & No & NA & NS \\
\hline $32^{\mathrm{b}}$ & 61 & NSGCT:EC & NA & NA & No & NA & $\begin{array}{l}\text { IGCNU, } \\
\text { Atrophy }\end{array}$ \\
\hline $33^{\mathrm{b}}$ & 69 & Seminoma & Right & 4.0 & Yes & No & IGCNU \\
\hline $34^{\mathrm{b}}$ & 66 & Seminoma & Left & 5.5 & Yes & Yes & NS \\
\hline $35^{\mathrm{b}}$ & 71 & NSGCT:EC,YST,T,polyembryoma & NA & NA & No & Yes & Normal \\
\hline $36^{\mathrm{b}}$ & 67 & NSGCT:EC,YST,CC & NA & 8.0 & Yes & Yes & NS \\
\hline $37^{\mathrm{b}}$ & 71 & Seminoma & Right & 5.8 & No & Yes & IGCNU, atrophy \\
\hline $38^{\mathrm{b}}$ & 69 & Seminoma & Left & 6.0 & No & No & NS \\
\hline $39^{\mathrm{b}}$ & 82 & NSGCT:EC & NA & 10.0 & Yes & NA & NS \\
\hline $40^{\mathrm{b}}$ & 65 & Seminoma & Left & 6.0 & No & No & Atrophy \\
\hline $41^{\mathrm{c}}$ & 69 & Seminoma & Left & 2.9 & No & Yes & Atrophy \\
\hline $42^{\mathrm{c}}$ & 77 & Seminoma & Right & NA & Yes & Yes & Atrophy \\
\hline $43^{\mathrm{c}}$ & 64 & Seminoma & Left & 2.0 & No & No & IGCNU, atrophy \\
\hline $44^{\mathrm{C}}$ & 64 & NSGCT:EC,YST,T & Right & 3.5 & Yes & Yes & Normal \\
\hline $45^{\mathrm{c}}$ & 65 & Seminoma & Right & 10.0 & Yes & Yes & NS \\
\hline $46^{\mathrm{c}}$ & 64 & Seminoma & Left & 2.7 & No & No & Normal \\
\hline $47^{\mathrm{c}}$ & 73 & Seminoma & Right & NA & No & No & Atrophy \\
\hline $48^{\mathrm{c}}$ & 72 & Seminoma & $\mathrm{NA}$ & NA & No & No & Atrophy \\
\hline $49^{\mathrm{c}}$ & 60 & Seminoma & Right & NA & No & Yes & IGCNU, atrophy \\
\hline $50^{\mathrm{c}}$ & 86 & Seminoma & Right & 6.5 & Yes & Yes & NS \\
\hline
\end{tabular}

Abbreviations: CC, choriocarcinoma; EC, embryonal carcinoma; NS, seminiferous tubules not seen in section; NSGCT, non-seminomatous germ cell tumour; S, seminoma; T, teratoma; TGC, trophoblastic giant cells; YST, yolk sac tumour.

${ }^{\mathrm{a}}$ Cases from The British Testicular Tumour Panel.

${ }^{\mathrm{b}}$ Cases from Barts and The London Hospitals.

${ }^{\mathrm{C}}$ Cases from Addenbrookes Hospital.

60 of above. However, they only report one spermatocytic seminoma, possibly because the tumour was not fully described at this time. Collins and Pugh ${ }^{12}$ report 32 germ cell tumours out of 86 tumours in men aged 60 and above, but do not report SS independently. Their later update in Pugh's classic textbook also does not distinguish between sperma- tocytic and classical seminomas; however, it gives and excellent overview of the other neoplasms diagnosed in the above 60 age group. He reports a total of 153 neoplasms of the testis and appendages. Forty-four $(29 \%)$ of these are germ cell tumours, including spermatocytic seminomas. Seventy (46\%) are lymphomas, $10(6 \%)$ are sex-cord/stromal 


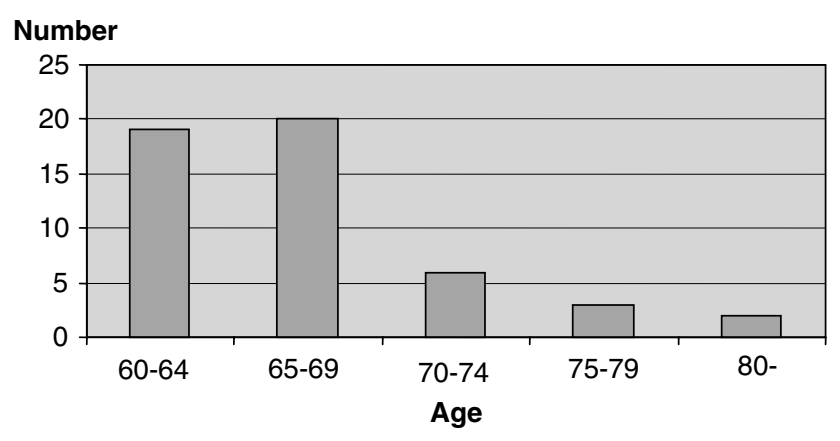

Figure 1 Frequency of germ cell tumours in the elderly.

tumours, while the remaining $29(19 \%)$ are a heterogenous mixture of sarcomas and other malignancies. ${ }^{14}$

Fergusson ${ }^{13}$ reports 18 germ cell tumours out of 51 cases of men aged 60 or above, but again does not report spermatocytic seminoma separately. Germ cell tumours in the elderly are also mentioned as occasional case reports, usually of embryonal carcinoma. ${ }^{15-18}$ The oldest patient we have found in the literature was a remarkable case of pure embryonal carcinoma in a man of $96 .{ }^{16}$ Spontaneous regression, ${ }^{19}$ necrosis, ${ }^{20}$ presentation as metastasis ${ }^{21,22}$ and bilateral tumours ${ }^{23}$ have all been reported in elderly men with seminoma. One report of two cases outlines problems in treating elderly men with seminomas. $^{24}$ We believe that ours is the largest series to date in patients over 60 .

The late presentation of germ cell tumours in this age group may be for a number of reasons. Education programmes in testicular self-examination are targeted largely at younger men and there may be a lack of self-awareness of the need for examination in this age group. Second, community doctors may be late in referring them to a specialist centre, especially if they feel that the lump is benign or non-neoplastic. Third, there may be resistance within elderly men to seek help for testicular lumps.

There are many differential diagnoses of a testicular mass in the elderly. Inflammatory conditions can usually, but not always, be excluded by clinical examination and investigations including ultrasound. Neoplastic differential diagnoses include, importantly, spermatocytic seminoma, and this was a major consideration when constructing the current series. Spermatocytic seminomas can be distinguished from seminoma on morphological grounds; by the presence in spermatocytic seminomas of three cell types, a scanty to absent lymphocytic infiltrate and presence of intratubular spermatocytic seminoma. IGCNU is absent in spermatocytic seminomas. ${ }^{4}$ In addition, placental alkaline phosphatase staining is absent to very scanty in spermatocytic seminoma. $^{25}$ The recently described anaplastic spermatocytic seminoma has a clinical behaviour similar to that of spermatocytic seminomas, and a similar immunoprofile. ${ }^{26}$ We have not seen a case of the rare sarcomatous transformation of spermatocytic seminomas in the British Testicular Tumour Panel series or in recent archives..$^{27,28}$

Large series of germ cell tumours all show similar rates of seminoma $v s$ non-seminoma with a rate varying from $46 \%$ seminoma in the series by $\mathrm{Pugh}^{8}$ to $53 \%$ seminoma for the series by Jacobsen. ${ }^{11,29,30}$ This contrasts markedly with this series in the elderly where there were a significantly greater number of seminomas $(82 \%)$.

Comparisons between the groups of non-seminomatous tumours are difficult due to the low numbers of cases in the current series. Mixed non-seminomas comprise $33 \%$ of the Jacobsen series and $31 \%$ of the von Hochstetter series whereas they comprise $16 \%$ of the current series. Pure tumour types (pure teratoma, choriocarcinoma, yolk sac or embryonal carcinoma) are $14 \%$ of the Jacobsen series and 16 of the von Hochstetter series whereas there was only one case of pure embryonal carcinoma $(2 \%)$ in the current series. Therefore, the elderly show a shift from pure tumour types towards mixed and seminomatous tumours.

The size of the tumours is significantly greater in this series than in other reported series. A recent assessment of size in germ cell tumours ${ }^{31}$ showed a reduction over time in mean diameter from $4 \mathrm{~cm}$ in the $1980 \mathrm{~s}$ to $2.5 \mathrm{~cm}$ currently. As half of these cases were diagnosed more than 30 years ago, the mean tumour diameter was calculated in only the recent cases, excluding those in the British Testicular Tumour Panel, and even in these the mean tumour diameter was $5.6 \mathrm{~cm}$. We conclude that elderly men do present with higher stage tumours than younger men. This may be for a number of reasons. First, the men may present to clinicians at a later stage, as they may be less likely to conduct testicular selfexamination and also less likely to present to their local physicians. However, it is also the case that there may be diagnostic delays due to lack of clinical examination of the testes in elderly men, or a perception that neoplasms in the elderly are less urgent than testicular masses in the younger male. Therefore, cure in the elderly male would appear to be more difficult than in younger men, because of a tendency to present at a higher stage and also less tolerance of the adverse effects of chemotherapy.

It was noted that there were more right testis than left testicular tumours. The increased frequency of right testicular tumours over left-sided tumours has been reported previously. ${ }^{32}$ This disparity is in keeping with the relative sizes of the left and right testes in humans.

IGCNU is well known to be commonly associated with germ cell tumours. Large series have described IGCNU adjacent to $98 \%$ of germ cell tumours, where sufficient seminiferous tubules could be assessed. ${ }^{33,34}$ In one assessment of the stroma adjacent to testicular tumours, tubular atrophy was seen adjacent to $36 \%$ of seminomas and $15 \%$ of nonseminomas and the amount of atrophy was inversely 
correlated with the amount of IGCNU. ${ }^{35}$ There was a strikingly low rate of IGCNU seen in association with these tumours in this series, and a correspondingly high rate of testicular atrophy, although only 17 tumours had sufficient seminiferous tubules to be reliably assessed. Two possible theories could explain this. First, the large size of tumours seen in this series might have led to more obliteration of the seminiferous tubules with IGCNU. Second, there could be a genuine loss of IGCNU with age. We are in favour of the second theory, as careful safeguards were made to exclude cases in which only a few tubules were identified, but IGCNU was not seen. Thus, these testicular germ cell tumours appear to be at the end of the spectrum in the pathogenesis of the disease. It could be hypothesised that these patients had ongoing IGCNU for many years, which failed to transform into an invasive tumour until later life. While much of the IGCNU eventually 'burns out', these tumours are the result of the extremely late event of late transformation of a limited amount of IGCNU into an invasive malignancy. The trend for these tumours to be seminomatous rather than transforming further (or initially) into non-seminomas is exaggerated in the elderly, where the plasticity of cell type, so typical in the young, has been lost.

We conclude that study of this age group has shown that germ cell tumours in the elderly present at a higher stage, and have a different disease profile than more typical cases, as well as shedding light on the pathogenesis of germ cell malignancy. Close examination of clinical outcomes in this group, in the setting of larger trials, may assist in better outcomes for this rare disease.

\section{Acknowledgement}

We gratefully acknowledge The Orchid Appeal for supporting this work.

\section{Disclosure/conflict of interest}

The authors affirm that they have no conflicts of interests arising from publication of this paper.

\section{References}

1 Brown LM, Pottern LM, Hoover RN, et al. Testicular cancer in the United States: trends in incidence and mortality. Int J Epidemiol 1986;15:164-170.

2 Purdue MP, Devesa SS, Sigurdson AJ, et al. International patterns and trends in testis cancer incidence. Int J Cancer 2005;115:822-827.

3 Pinkerton CR. Malignant germ cell tumours in childhood. Eur J Cancer 1997;33:895-901.

4 Eble JN. Spermatocytic seminoma. Hum Pathol 1994;25: 1035-1042.
5 Looijenga LH, Hersmus R, Gillis AJ, et al. Genomic and expression profiling of human spermatocytic seminomas: primary spermatocyte as tumorigenic precursor and DMRT1 as candidate chromosome 9 gene. Cancer Res 2006;66:290-302.

6 Shamash J, Powles T, Ansell W, et al. GAMEC-a new intensive protocol for untreated poor prognosis and relapsed or refractory germ cell tumours. Br J Cancer 2007;97:308-314.

7 Horwich A, Shipley J, Huddart R. Testicular germ-cell cancer. Lancet 2006;367:754-765.

8 Thackray AC, Crane WA. Seminoma. In: Pugh RC (ed). Pathology of the Testis, 1st edn. Blackwell Scientific: Oxford, 1976, pp 164-198.

9 Treves G. Two cases of seminoma in subjects over 70 years of age. Arch De Vecchi Anat Patol 1958;28: 757-771.

10 Abell MR, Holtz F. Testicular and paratesticular neoplasms in patients 60 years of age and older. Cancer 1968;21:852-870.

11 Krag JG, Barlebo H, Olsen J, et al. Testicular germ cell tumours in Denmark 1976-1980. Pathology of 1058 consecutive cases. Acta Radiol Oncol 1984;23: 239-247.

12 Collins DH, Pugh RC. Classification and frequency of testicular tumours. Br J Urol 1964;36(Suppl 1-11).

13 Fergusson JD. Tumours of the testis. Br J Urol 1962;34:407-421.

14 Pugh RCB. Testicular tumours-Introduction. In: Pugh RCB (ed). Pathology of the Testis, 1st edn. Blackwell Scientific Publications: Oxford, 1976, pp 139-163.

15 Gohji K, Watsuji T, Ubai T, et al. Embryonal carcinoma of the testis associated with prostate cancer in a 72-year-old man. Int J Urol 2001;8:719-721.

16 Tuttle Jr JP, Pratt-Thomas HR, Thomason WB. Embryonal carcinoma of the testis in elderly men. J Urol 1977;118:1070-1072.

17 Morrow TW, Soloway MS. Re: embryonal carcinoma of the testis in elderly men. J Urol 1978;119:709-710.

18 Steinbronn DV, Hicks TH, Carrel Jr WH. Mixed germ cell testis tumor in an 86-year-old man. J Urol 1999;162:161.

19 Balzer BL, Ulbright TM. Spontaneous regression of testicular germ cell tumors: an analysis of 42 cases. Am J Surg Pathol 2006;30:858-865.

20 Yamamoto S, Hashimoto T, Nojima M, et al. Testicular seminoma associated with massive necrosis. Int J Urol 2006;13:1262-1263.

21 Akst LM, Discolo C, Dipasquale B, et al. Metastatic seminoma with cervical lymphadenopathy as the initial manifestation. Ear Nose Throat J 2004;83: 356-359.

22 Berdjis N, Offergeld C, Lossnitzer A, et al. Solitary cervical lymph node manifestation of a seminoma without detectable primary. Urol Int 2001;67:165-167.

23 Ohyama C, Kyan A, Satoh M, et al. Bilateral testicular tumors: a report of nine cases with long-term followup. Int J Urol 2002;9:173-177.

24 Rentinck ME, Nieboer P, Sleijfer DT, et al. Chemotherapy for metastatic seminoma in elderly patients. Anticancer Res 2003;23:3093-3096.

25 Cummings OW, Ulbright TM, Eble JN, et al. Spermatocytic seminoma: an immunohistochemical study. Hum Pathol 1994;25:54-59.

26 Albores-Saavedra J, Huffman H, Alvarado-Cabrero I, et al. Anaplastic variant of spermatocytic seminoma. Hum Pathol 1996;27:650-655. 
27 Matoska J, Talerman A. Spermatocytic seminoma associated with rhabdomyosarcoma. Am J Clin Pathol 1990;94:89-95.

28 True LD, Otis CN, Delprado W, et al. Spermatocytic seminoma of testis with sarcomatous transformation. A report of five cases. Am J Surg Pathol 1988;12:75-82.

29 von Hochstetter AR, Hedinger CE. The differential diagnosis of testicular germ cell tumors in theory and practice. A critical analysis of two major systems of classification and review of 389 cases. Virchows Arch A Pathol Anat Histol 1982;396:247-277.

30 Teppo L. Malignant testicular tumours in Finland. Acta Pathol Microbiol Scand 1969;75:18-26.

31 Bhardwa JM, Powles T, Berney D, et al. Assessing the size and stage of testicular germ cell tumours: 1984-2003. BJU Int 2005;96:819-821.
32 Roychoudhuri R, Putcha V, Moller H. Cancer and laterality: a study of the five major paired organs (UK). Cancer Causes Control 2006;17:655-662.

33 Coffin CM, Ewing S, Dehner LP. Frequency of intratubular germ cell neoplasia with invasive testicular germ cell tumors. Histologic and immunocytochemical features. Arch Pathol Lab Med 1985;109 $555-559$.

34 Jacobsen GK, Henriksen OB, von der Maase $H$. Carcinoma in situ of testicular tissue adjacent to malignant germ-cell tumors: a study of 105 cases. Cancer 1981;47:2660-2662.

35 Oosterhuis JW, Kersemaekers AM, Jacobsen GK, et al. Morphology of testicular parenchyma adjacent to germ cell tumours. An interim report. APMIS 2003;111: 32-40. 